\title{
Endocrine differentiation of fetal ovaries and testes of the spotted hyena (Crocuta crocuta): timing of androgen-independent versus androgen-driven genital development
}

\author{
P Browne, N J Place ${ }^{1}$, J D Vidal, I T Moore², G R Cunha ${ }^{3}$, S E Glickman and A J Conley \\ Department of Population Health and Reproduction, School of Veterinary Medicine, University of California, Davis, \\ California 95616, USA, ${ }^{1}$ Department of Psychology, University of California, Berkeley, California, USA, ${ }^{2}$ Department \\ of Biological Sciences, Virginia Polytechnic Institute, Blacksburg, Virginia, USA and ${ }^{3}$ Department of Anatomy, \\ University of California, San Francisco, California, USA
}

Correspondence should be addressed to A J Conley; Email: ajconley@ucdavis.edu

\begin{abstract}
Female spotted hyenas (Crocuta crocuta) have an erectile peniform clitoris and a pseudoscrotum but no external vagina, all established by day 35 of a 110-day gestation. Recent studies indicate that these events are androgen-independent, although androgen secretion by fetal ovaries and testis was hypothesized previously to induce phallic development in both sexes. We present the first data relating to the capacity of the ovaries and testes of the spotted hyena to synthesize androgens at different stages of fetal life. Specifically, spotted hyena fetal gonads were examined by immunohistochemistry at GD 30, 45, 48, 65, and 95 for androgen-synthesizing enzymes, as related to the morphological development. Enzymes included 17 $\alpha$-hydroxylase/17,20-

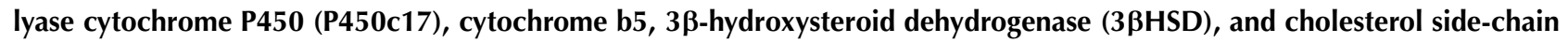
cleavage cytochrome P450 (P450scc). Anti-Müllerian-hormone (AMH) expression was also examined. AMH was strongly expressed in fetal Sertoli cells from GD 30 and after. P450c17 expression was detected in Leydig cells of developing testes and surprisingly in Müllerian duct epithelium. Fetal ovaries began to organize and differentiate by GD 45, and medullary cells expressed P450c17, cytochrome b5, 33HSD, and P450scc. The findings support the hypothesis that external genital morphology is probably androgen-independent initially, but that fetal testicular androgens modify the secondary, male-specific phallic form and accessory organs. Fetal ovaries appear to develop substantial androgen-synthesizing capacity but not until phallic differentiation is complete, i.e. after GD 45 based on circulating androstenedione concentrations. During late gestation, fetal ovaries and testes synthesize androgens, possibly organizing the neural substrates of aggressive behaviors observed at birth in spotted hyenas. These data provide an endocrine rationale for sexual dimorphisms in phallic structure and reveal a potential source of androgenic support for neonatal aggression in female and male $C$. crocuta.
\end{abstract}

Reproduction (2006) 132 649-659

\section{Introduction}

The external genitalia of the female spotted hyena (Crocuta crocuta) have been of interest since the first scientific descriptions over a century ago (see Matthews 1939, Glickman 1995). Specifically, at birth, female spotted hyenas lack a vulva, possessing instead an erectile peniform clitoris that is comparable in size with the penis, through which they urinate, copulate, and give birth (Drea et al. 1999). The apparent 'virilization' of female spotted hyenas seems to challenge the established precepts of mammalian sex differentiation, i.e., that female reproductive development occurs by a 'default' pathway. According to the traditional view (Wilson et al. 1995), male development in eutherian mammals is initiated by a testis-determining factor, the Y-linked SRY gene of some species (Sinclair et al. 1990), in concert with autosomal genes that together direct testicular morphogenesis within the genital ridge. Newly formed fetal testes are functional as endocrine organs (Wilson et al. 1995). Testosterone secretion by the fetal Leydig cells stabilizes the Wolffian ducts, ensuring complete male duct formation. Testosterone is also converted to dihydrotestosterone (DHT) within the primordial genital tissues, promoting prostatic development and fusion of the urethral folds to form the penile urethra. Fetal Sertoli cells are also active endocrinologically secreting anti-Müllerian hormone 
$(\mathrm{AMH})$ that induces Müllerian duct regression, eventually allowing testicular descent and completion of differentiation of the male soma. In contrast, female gonads develop as ovaries that are relatively inactive endocrinologically, in which case there is no fusion of the urethral folds, and the genital swellings develop as an external vagina instead of a scrotum. Consequently, there has been considerable speculation as to how the external genitalia of female spotted hyenas become 'virilized', and how mechanisms of mammalian sexual differentiation in this species differ from the eutherian norm.

Anatomical masculinization in female spotted hyenas is obvious early during fetal development (Fig. 1), and though exact cellular sources remain poorly defined, was long thought to reflect in utero androgen exposure (Place \& Glickman 2004). Both male and female gonads were proposed to be sites of androgen synthesis during fetal life from studies on field specimens (Lindeque \& Skinner 1982). However, fetal ages were likely underestimated, based on the examination of more accurately staged tissues from pairing and/or observed mating dates (Licht et al. 1998). Licht et al. suggested that androgen from the fetal ovary might perhaps influence clitoral development later during gestation, but considered it highly unorganized at stages early enough to influence genital tubercle morphogenesis (Licht et al. 1998). More recent studies showed that genital tubercle differentiation is not only sexually dimorphic (Cunha et al. 2003) but also androgen sensitive (Cunha et al. 2005). The penis is longer and thicker than the clitoris (Frank et al. 1990), with an angular (rather than a rounded) glans, and a narrower, less elastic urogenital meatus (Frank et al.

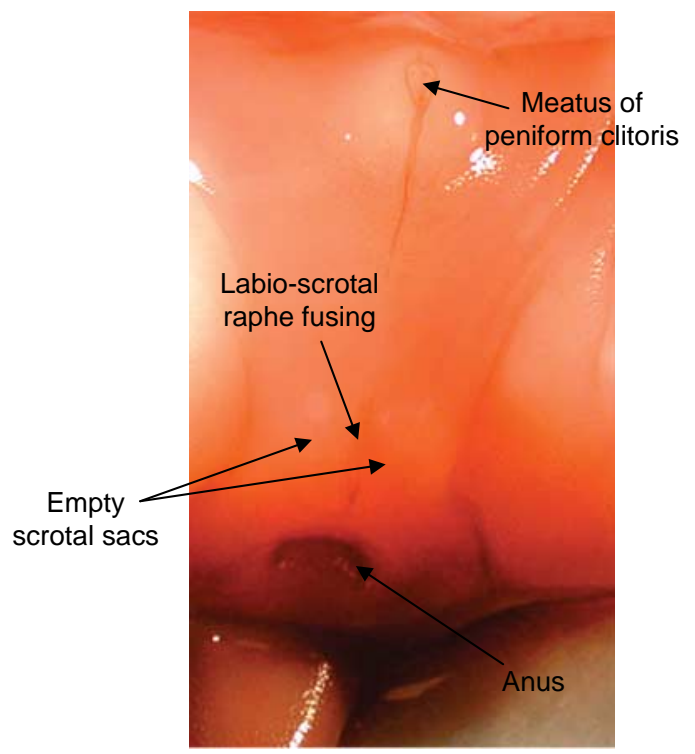

Figure 1 External genital development of a female spotted hyena fetus at GD 65. Note the swellings of the empty scrotal sacs, labio-scrotal fusion extending toward the meatus at the tip of the developing peniform clitoris.
1990, Drea et al. 1998). Internally, there are also sex differences in positioning of the retractor muscles, location of erectile tissues and surrounding fibroelastic tunica, and 'pleating' of the urogenital sinus (Neaves et al. 1980, Cunha et al. 2003, 2005). Treatment with anti-androgens during fetal life transforms the male penile phenotype into the clitoral phenotype of the female spotted hyena (Forger et al. 1996, Drea et al. 1998, Cunha et al. 2005). Evidently, androgens arriving from the placenta (Licht et al. 1992, Yalcinkaya et al. 1993) are insufficient to 'masculinize' the female genital tubercle, which in males occurs between 30 and 45 days of gestational age (Cunha et al. 2005). However, the potential for steroid synthesis by hyena fetal testes compared with ovaries has been a matter of speculation and based only on the degree of cellular 'organization' during the early stages of fetal development.

Thus, the present study was conducted to reevaluate the steroidogenic potential of the fetal gonads of the spotted hyena using immunohistochemistry. Two principle issues were addressed: (1) are the fetal testes capable of synthesizing androgen at the time of phallic differentiation and (2) are the fetal ovaries capable of synthesizing androgens and, if so, when? Steroidogenic enzyme expression was examined in tissue and available samples of fetal blood were analyzed for androgen concentrations. Androgen synthesis is directly dependent on the expression of the enzyme $17 \alpha$-hydroxylase/17,20-lyase cytochrome P450 (P450c17), a redox partner and an accessory protein, cytochrome b5 (Mapes et al. 1999, 2002) that specifically supports 17,20-lyase activity (Miller 2005). Additional key enzymes include $3 \beta$-hydroxysteroid dehydrogenase $(3 \beta \mathrm{HSD})$ and cholesterol side-chain cleavage cytochrome P450 (P450scc) providing substrate, if this is not available otherwise (Conley \& Bird 1997). Therefore, expression of these enzymes, and of $\mathrm{AMH}$ as a Sertoli cell marker, was examined by immunohistochemistry of the fetal ovaries and testes of spotted hyenas from early to late gestation.

\section{Materials and Methods}

\section{Tissue collection}

Male and female hyenas were housed separately at the Field Station for the Study of Behavior, Ecology, and Reproduction at the University of California, Berkeley until reproductively mature females demonstrated signs of behavioral estrus. At that point, a mature male was introduced and the pair was observed for signs of female receptivity. Gestational age in days (GD) was estimated from the day of observed mating after pregnancies were confirmed by trans-abdominal ultrsonography (Place et al. 2002). Fetal specimens were obtained by hysterotomy from a total of eight pregnancies at gestational days (GD) 30, 45, 48, 65 and 95 as outlined 
in Table 1. All pregnancies were deemed normal and fetuses were of a size consistent with the expected fetal age based on estimates made from the time of observed mating, as reported in an earlier paper (Cunha et al. 2005). Procedures were approved by the Animal Care and Use Committee of the University of California at Berkeley.

\section{Immunohistochemistry}

Anti-Müllerian hormone and steroidogenic enzyme expression were examined in fixed gonads and adjacent tissues of hyena fetuses. Sex of fetuses less than GD 65 was determined from genomic DNA extracted from frozen tissue by PCR amplification of SRY (Pomp et al. 1995). Tissues were fixed for $24 \mathrm{~h}$ in $4 \%$ paraformaldahyde at $4{ }^{\circ} \mathrm{C}$ immediately following dissection, dehydrated in a graded ethanol series, paraffin-embedded, and sectioned at $5 \mu \mathrm{m}$. Immunohistochemical localization of all proteins was performed using an avidin-biotin-peroxide complex method (VECTASTAIN Elite ABC kits, Vector Laboratories, Burlingame, CA, USA). Tissue sections were deparaffinized using CitriSolv (Fisher HealthCare, Houston, TX, USA) and rehydrated in a graded ethanol series. Endogenous peroxidase activity was blocked to reduce background staining by incubating tissue sections in $0.3 \% \mathrm{H}_{2} \mathrm{O}_{2}$ for $30 \mathrm{~min}$ and rinsed in buffer $(0.1 \mathrm{M} \mathrm{PBS}$, $\mathrm{pH} 7.2$ with $0.3 \%$ Triton $X)$ for 5 min. Staining was optimized for P450c17 and 3 $\beta$-HSD by heating sections to $95^{\circ} \mathrm{C}$ for $25 \mathrm{~min}$ in citrate buffer $(\mathrm{pH} \mathrm{6.0)}$ in a rice steamer with continuous temperature monitoring. Non-specific staining was blocked by incubating sections with $1.5 \%$ normal serum of the species in which the secondary antibody was raised for $20 \mathrm{~min}$. Tissue sections were incubated at $4{ }^{\circ} \mathrm{C}$ for $16 \mathrm{~h}$ with the following primary antisera: AMH (1:1000 polyclonal goat antiserum raised against a 20 amino acid C-terminal sequence of the human protein, Santa Cruz Biotechnology, Santa Cruz, CA, USA), P450c17 $(1: 2000$, rabbit polyclonal anti-bovine protein, this laboratory), cytochrome b5 (1:3000, polyclonal rabbit anti-human recombinant protein, this laboratory), 3 $\beta$-HSD (1:2000, polyclonal rabbit anti-human ovarian purified protein, Dr J lan Mason, Royal Infirmary of Edinburgh NHS Trust, Edinburgh, Scotland), P450scc (1:2000, polyclonal rabbit anti-human purified protein, Dr W L Miller, University of California San Francisco,

Table 1 Numbers of male (M) and female (F) spotted hyena fetuses collected at indicated gestational stages (days).

\begin{tabular}{lccl}
\hline Fetal age (days) & Males & Females & Fetal sex within pregnancies \\
\hline 30 & 2 & 2 & $(\mathrm{~F}, \mathrm{M})^{\mathrm{a}} ;(\mathrm{F}, \mathrm{M})^{\mathrm{a}}$ \\
$45 ; 48$ & $1^{\mathrm{a}}$ & $3^{\mathrm{a}}$ & $(2 \mathrm{~F}, 1 \mathrm{M})^{\mathrm{b}} ; 1 \mathrm{~F}$ \\
65 & 1 & 1 & $(\mathrm{~F}, \mathrm{M})^{\mathrm{a}}$ \\
95 & 2 & 2 & $(\mathrm{~F}, \mathrm{M})^{\mathrm{a}} ; 1 \mathrm{~F} ; 1 \mathrm{M}$ \\
\hline
\end{tabular}

${ }^{\mathrm{a}}$ Mixed-sex twins. ${ }^{\mathrm{b}}$ Mixed-sex triplets.
San Francisco, CA, USA), and aromatase cytochrome P450 (1:1000, polyclonal rabbit anti-human recombinant protein, Dr Nobuhiro Harada, Fujita Health University School of Medicine, Aichi, Japan) diluted in PBS. The specificity of all antisera was confirmed by western immunoblot of hyena tissues where single immunoreactive bands were observed at the molecular sizes anticipated for each protein (data not shown). Normal serum was substituted for the primary antibody in negative controls for both steamed and non-steamed sections. Sections were incubated with biotinylated secondary antibody and tertiary avidin-biotin complex for 30 min each. Antibody binding was visualized using peroxidase substrate kits (3-amino-9-ethylcarbazole (AEC), Vector Laboratories, Burlingame, CA, USA), counterstained with hematoxylin, mounted with an aqueous mounting media, and cover-slipped.

\section{Steroid hormone analysis}

Trunk blood was collected from one female of triplets at GD 45, and a male and female of twins at GD 65, shortly after separation from the placenta. Cardiac blood was similarly collected from twin male and female fetuses at GD 95. Plasma was isolated and used to measure steroid concentrations. Samples were analyzed in duplicate by RIA for steroid concentrations following the procedures of Wingfield et al. (1991). Androstenedione (A4) concentrations were measured by direct assay following organic extraction of the plasma, while testosterone (T), estradiol (E2), and dihydrotestosterone (DHT) concentrations were assayed after organic extraction and celite column chromatography. Samples were corrected for individual extraction efficiency. Each steroid was analyzed in a single assay with the following intraassay variations (A4, 3.2\%; T, 4.7\%; E2, 2.1\%; DHT, $4.4 \%$ ) and limits of detection (A4, $0.5 \mathrm{ng} / \mathrm{ml} ; \mathrm{T}, 0.1 \mathrm{ng} /$ $\mathrm{ml}$; $2,0.2 \mathrm{ng} / \mathrm{ml}$; DHT, $0.2 \mathrm{ng} / \mathrm{ml}$ ).

\section{Results}

As noted earlier, the weights and gross anatomy of all fetuses were consistent with the normal development expected for the gestational age determined from the date of observed mating, the details of which have been published previously (Cunha et al. 2005). The differentiation of male and female gonads recovered from fetuses at GD 30 is shown in Fig. 2A-F. Testicular cords were already recognizable and $\mathrm{AMH}$ expression was evident in the cytoplasm of developing Sertoli cells within the cords in the cortical regions of the developing testis (Fig. 2A). The expression of P450c17 (Fig. 2B), and cytochrome b5 and $3 \beta \mathrm{HSD}$ (data not shown), was also evident in the cytoplasm of presumptive Leydig cells but staining was much less intense. However, intense cytoplasm-specific staining for P450c17 was observed 

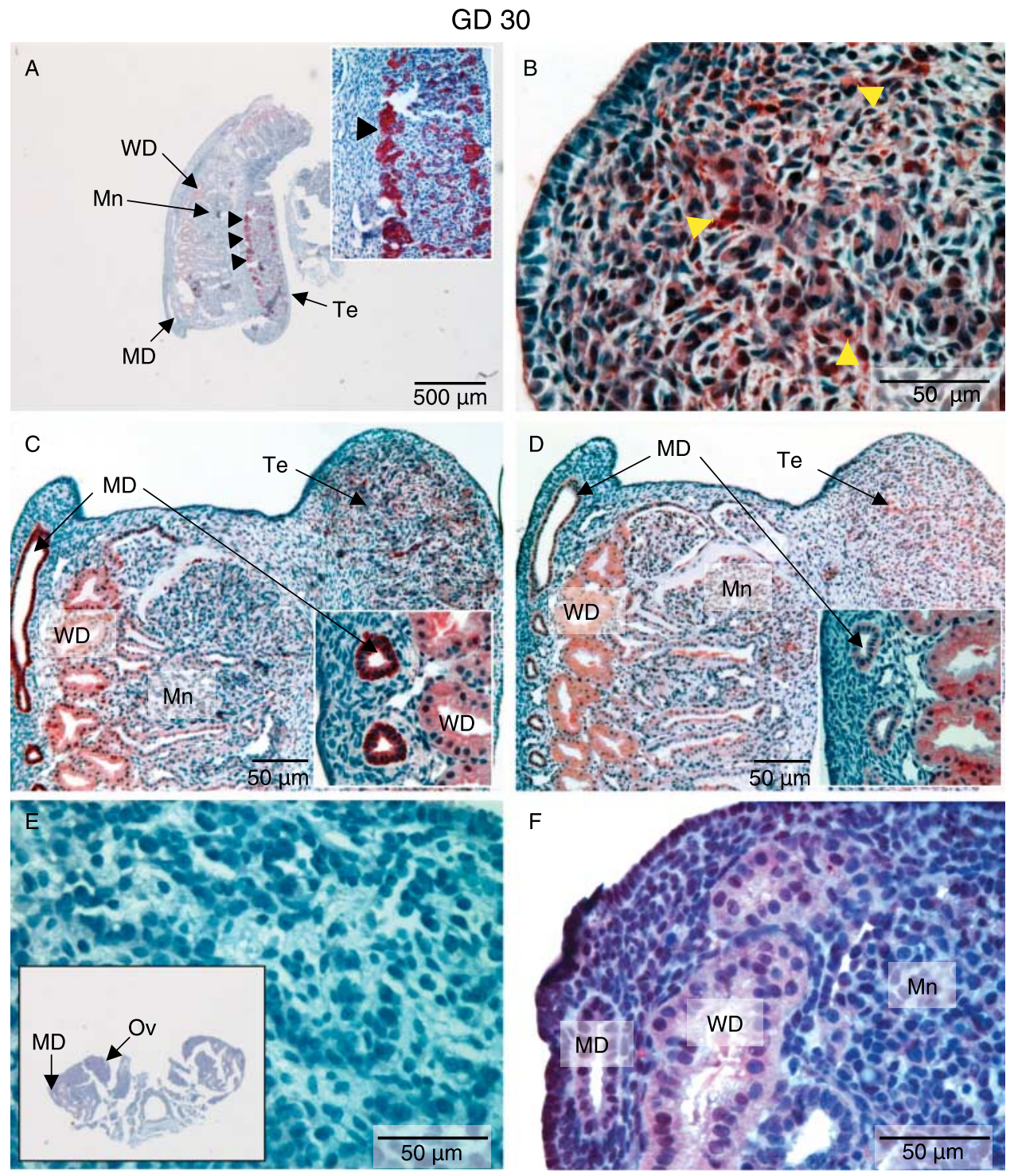

Figure 2 Developing gonads and mesonephros from male ((A)-(D)) and female ((E) and (F)) spotted hyena fetuses recovered at 30 days of gestation. (A) Immunohistochemistry for anti-Müllerian hormone $(\mathrm{AMH})$ in a section through the genital ridge of a male fetus showing cytoplasmic expression (in red) in Sertoli cells (arrowheads) of the testis (Te). The mesonephros (Mn), Wolffian duct (WD), and Müllerian duct (MD) are also indicated. Note the organization of cords particularly around the margins of the testis (insert). (B) Immunohistochemistry of fetal testis showing evidence of Leydig cell differentiation and expression of P450c17 (arrows). (C) Immunohistochemistry showing evidence of expression of P450c17 in the MD of a male fetus. Note that lighter, non-specific staining was evident in cells lining the WD and mesonephric tubules, as also seen in sections stained for $\mathrm{AMH}$ (see (A)). (D) Adjacent sections incubated with antisera pre-adsorbed with purified recombinant P450c17. Note the decrease in intensity of staining in the MD and testis but no change in background staining of the cells lining the WD and mesonephric tubules. Insert shows the region of $\mathrm{MD}$ at higher magnification. (E) Immunohistochemistry showing a lack of AMH expression in a section through the genital ridge of a female fetus. Insert provides a view of the entire ovary at low magnification. The MD and the region of ovarian development (Ov) are indicated. (F) The MD, WD, and $\mathrm{Mn}$ at higher magnification of a section showing the lack of expression of P450c17.

in the epithelium of the Müllerian ducts and less intense staining was present within the Wolffian duct and mesonephric tubules (Fig. 2C and insert). Pre-adsorption of the P450c17 antiserum with purified recombinant P450c17 protein markedly reduced staining in both the Müllerian duct epithelium and the testis, but did not alter the low level of staining in the Wolffian ducts and the mesonephric tubules (Fig. 2D and insert). In contrast, the genital ridge of the female lacked obvious cellular organization and there was no detectable evidence of AMH (Fig. 2E), or comparable P450c17, cytochrome b5 or $3 \beta \mathrm{HSD}$ expression in either developing gonads or the Müllerian duct epithelium (Fig. 2F).

Gonadal size was much increased in the sibling male and female fetuses recovered at GD 45. By this stage, fetal testicular organization into seminiferous tubules was virtually complete and $\mathrm{AMH}$ expression within the Sertoli cells was evident throughout the gonad 
(Fig. 3A). The differentiation of Leydig cells within the testicular interstitium was equally evident at GD 45 based on the markedly increased expression of P450c17 in the cytoplasm of Leydig cells, which was the mirror image of AMH (Fig. 3B). Leydig cells also expressed $3 \beta \mathrm{HSD}$ (Fig. 3C) and cytochrome b5 (data not shown). The organization and differentiation of the fetal ovaries at GD 45 and 48 lagged behind the fetal testes (Fig. 3D-G). Despite a comparable increase in size, there was no evidence of AMH expression in the fetal ovary (Fig. 3D). Ovarian organization was limited to the presence of a thin layer of compact cells in the cortex and the development of cellular cords in the medulla. However, cells in the cortex stained strongly for P450c17 (Fig. 3E) and cytochrome b5 (Fig. 3F). The beginning of medullary cord development was highlighted by the expression of P450c17 and cytochrome b5 (Fig. 3G) in the cells separating the cords. This contrasted with the lack of organization in the ovarian specimen collected at GD 48, which, although at a slightly later estimated fetal age, showed little evidence of cord development and only a few scattered cells expressing P450c17 (Fig. 3H). In fact, the vast majority of cells showed no evidence of steroidogenic differentiation.

Testis morphology and differentiation changed little from GD 45 to 65. AMH expression in Sertoli cells remained intense, and germ cells that lacked staining became more obvious within the seminiferous tubules (Fig. 4A and insert). Similarly, there was no change in the intensity or pattern of expression of $3 \beta \mathrm{HSD}$, which was uniformly distributed throughout the interstitial compartment of the fetal testis (Fig. 4B) within the cytoplasm of the Leydig cells (Fig. 4C). An identical pattern of expression of P450c17 was seen throughout the testis (Fig. 4D) with intense immunolocalization in the interstitial compartment (Fig. 4E). The same was true of the accessory protein, cytochrome b5 (Fig. 4F and insert). However, ovarian differentiation was largely advanced in the twin female fetus recovered at GD 65 when compared with the development at GD 45 or 48. The ovary still lacked any detectable AMH expression, but there was a considerable expansion of cortical width and recognizable primordial germ cells within this region of the gonad (Fig. 5A). The medulla

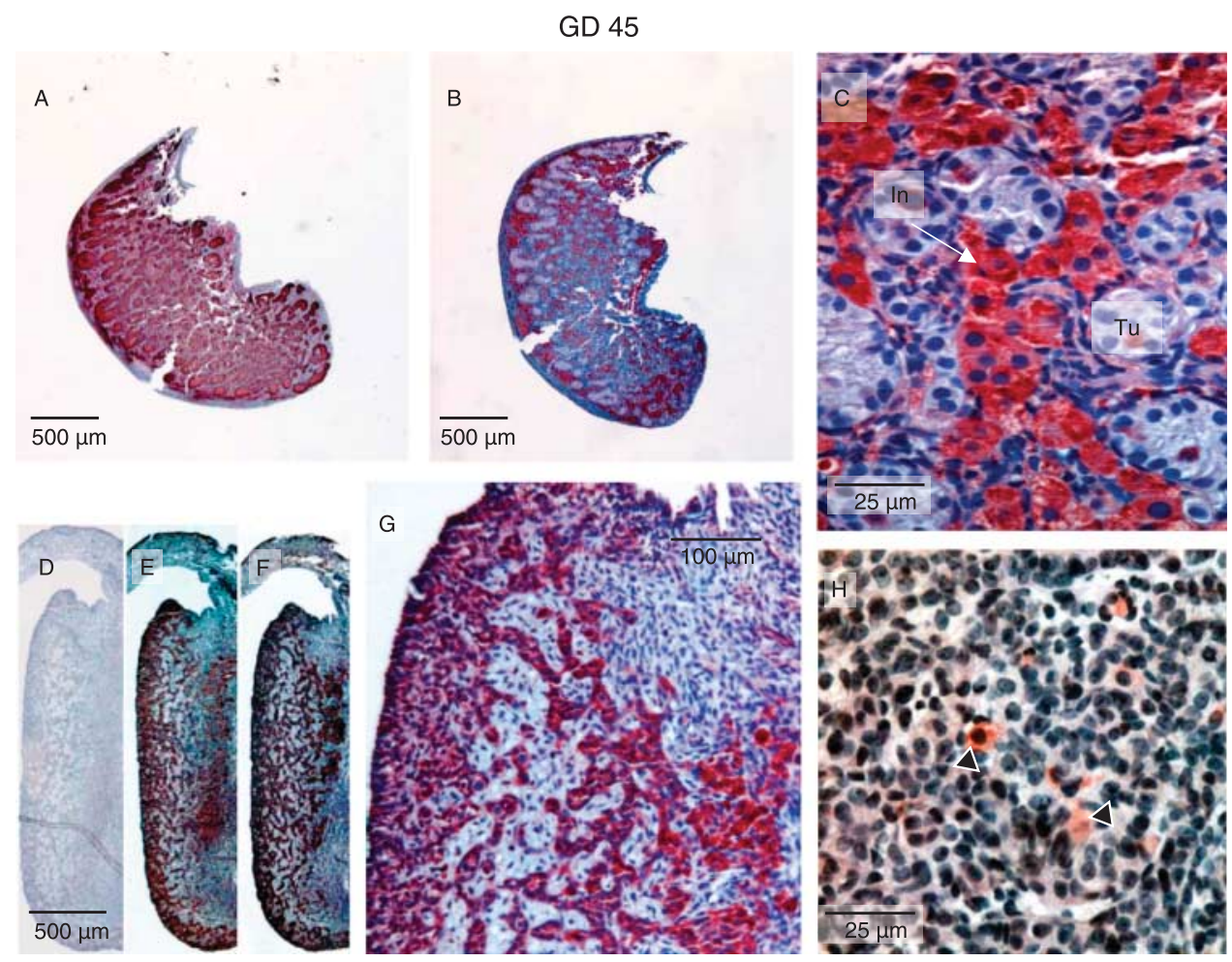

Figure $3 \mathrm{Immunohistochemistry} \mathrm{for} \mathrm{expression} \mathrm{(in} \mathrm{red)} \mathrm{of} \mathrm{anti-Müllerian} \mathrm{hormone} \mathrm{(AMH),} 3 \beta$-hydroxysteroid dehydrogenase ( $3 \beta \mathrm{HSD}$ ), and $17 \alpha$ hydroxylase cytochrome P450 (P450c17) in spotted hyena fetal testes at GD 45 ((A)-(C)) and fetal ovaries at GD 45 ((D)-(G)) and 48 (H). (A) AMH expression is strong in Sertoli cells within the well-organized seminiferous tubules. (B) $3 \beta H S D$ expression is intense in cells of the interstitial compartment. (C) Higher magnification showing strong P450c17 expression in cells of the testicular interstitial compartment. (D) Fetal ovary lacking evidence of AMH expression. (E) Fetal ovary showing expression of P450c17 in the cortex and developing medulla. (F) Fetal ovary showing similar pattern of expression of cytochrome b5. (G) Higher power view of fetal ovarian cytochrome b5 expression showing early organization of medullary cords. $(\mathrm{H})$ Less organized, less differentiated fetal ovary showing little evidence of organization and with few cells that stain positively for P450c17 (arrowheads). Note that the male fetus represented in (A)-(C) was a sibling to the female depicted in (D)- $(\mathrm{G})$ but that depicted in $(\mathrm{H})$ was from a different pregnancy. 

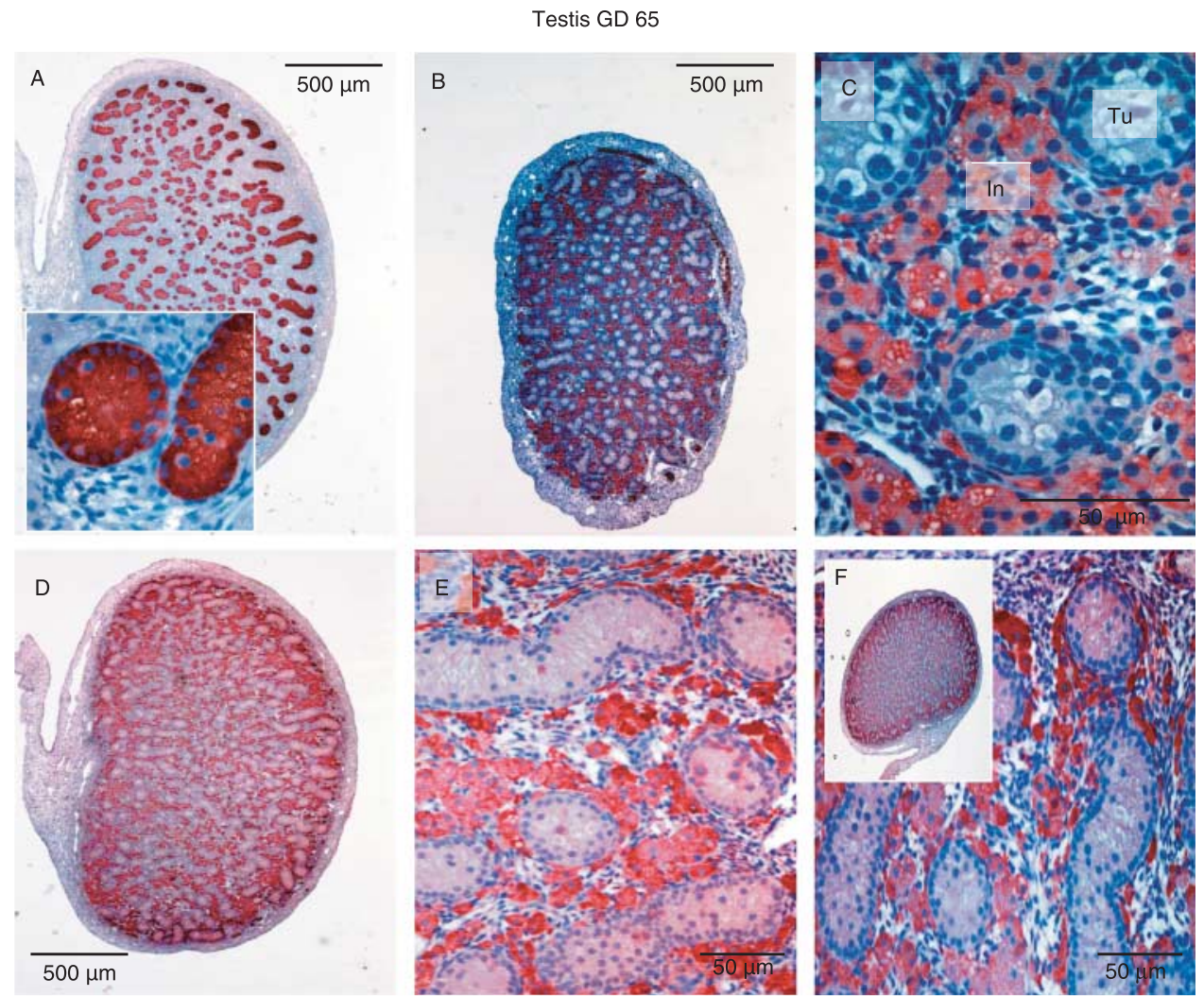

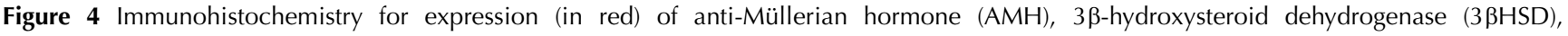
$17 \alpha$-hydroxylase cytochrome P450 (P450c17), and cytochrome b5 in testes of a spotted hyena fetus recovered at GD 65. (A) AMH expression in fetal Sertoli cells within the seminiferous tubules. Germ cells can be seen to standout at higher magnification (insert). (B) $3 \beta \mathrm{HSD}$ expression was intense throughout the interstitial compartment. (C) Higher magnification shows lipid-laden Leydig cells express 3ßHSD. (D) P450c17 expression was equally intense in the testicular interstitium. (E) Higher magnification shows Leydig cell expression of P450c17. (F) Cytochrome b5 expression was equally intense throughout the testis (insert) and also localized to Leydig cells.

was distinct, and more clearly separated from the cortex, especially when sections were immunostained. The expression of $3 \beta \mathrm{HSD}$ was restricted to cells within the ovarian medulla (Fig. 5B) and specifically to cells with increased cytoplasmic volume that were numerous but scattered throughout this region (Fig. 5C). Only occasional $3 \beta \mathrm{HSD}$-positive cells were found in the cortex, confined mostly to the inner cell layers. Ovarian expression of P450c17 was intense in the specimen examined at GD 65 (Fig. 5D), and as for $3 \beta \mathrm{HSD}$, expression was greatest in larger, cytoplasmrich medullary cells (Fig. 5E) that had a general appearance consistent with steroidogenic capacity. However, P450c17 expression was also detected in cells of the ovarian cortex, particularly those forming cords through the outer cortex between germ cell nests (Fig. 5D). Cytochrome b5 expression was equally high in the larger medullary cells and more modest staining was observed in the outer cortical cells (Fig. 5F and insert). The ovarian medulla was equally prominent at GD 95 and as intensely positive for $3 \beta \mathrm{HSD}$ (Fig. 6A), P450c17, and cytochrome b5 (data not shown), as the testicular interstitium (Fig. 6B). This was consistent among the specimens available. AMH expression in Sertoli cells remained strong in the testes at this stage, but was not detected in ovaries (data not shown).

The potential for fetal gonads to synthesize their own substrates for sex steroid synthesis, rather than utilize circulating pregnanes, was investigated by examining the expression of P450scc. P450scc was first evident in the Sertoli cells of the developing testes at GD 30 (Fig. 7A), but by GD 45 (Fig. 7C) and after (Fig. 7E and G), the highest expression levels were interstitial. Faint staining was detectable in testicular tubules at GD 45 and 65 (Fig. 7C and E), but was absent at GD 95 where expression was detected in Leydig cells only (Fig. 7G). In contrast to the testes, no specific P450scc expression was detected in the ovaries at GD 30 (Fig. 7B), but organization of cortical cords at GD 45 was associated with P450scc expression in ovarian interstitial cells (Fig. 7D). By GD 65, the larger cells of the medullary region of the developing ovary were strongly positive for P450scc, whereas the cortex was virtually devoid of staining (Fig. 7F). The same general pattern was also seen in the ovary at GD 95 (Fig. 7H). P450arom was not detected in either male or female gonads at GD 30, 45, 65, or 95, though expression 


\section{Ovary GD 65}
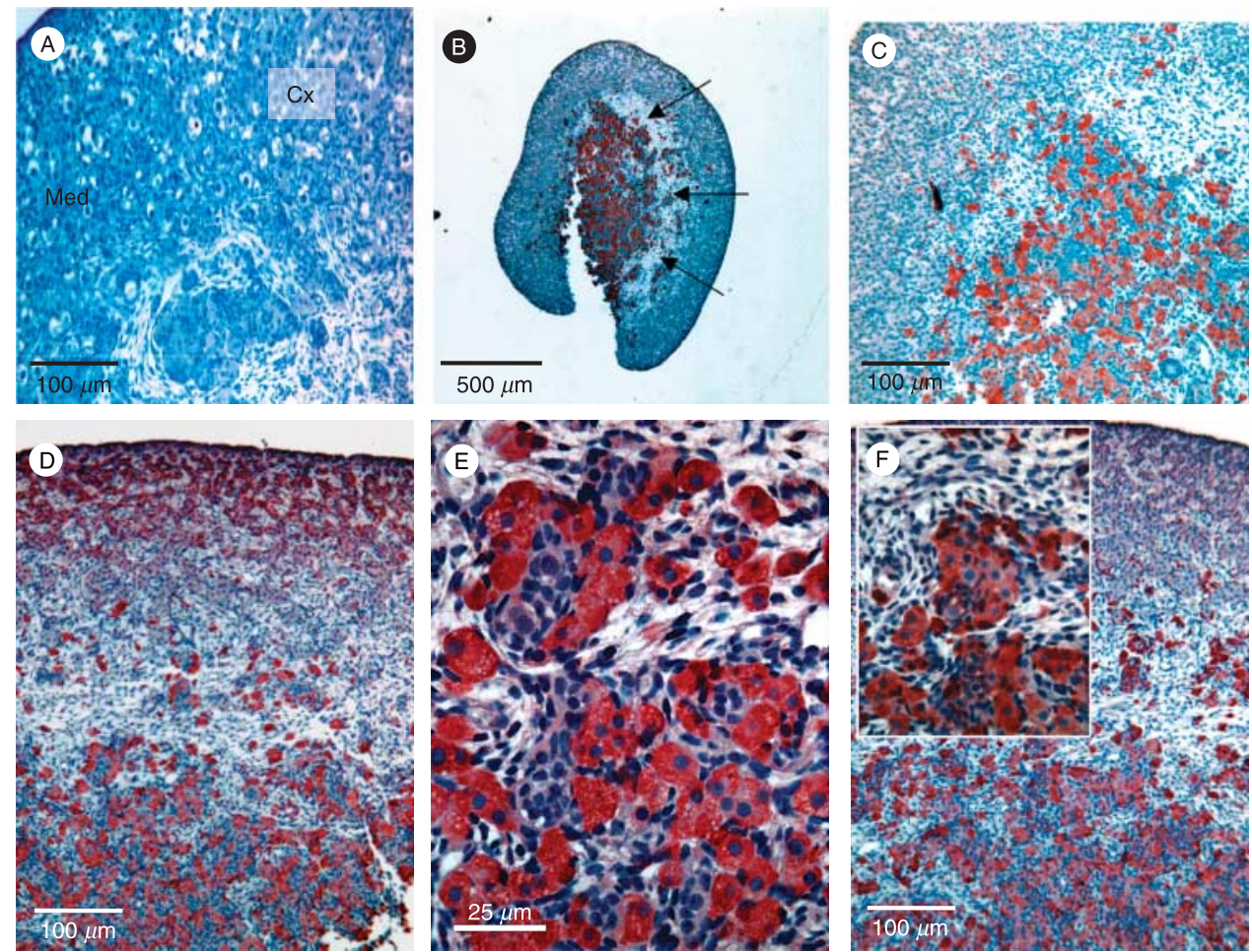

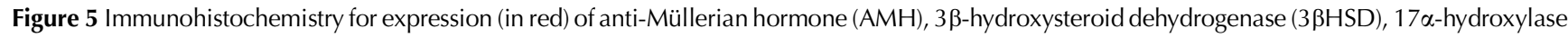
cytochrome P450 (P450c17), and cytochrome b5 in the ovary of a spotted hyena fetus recovered at GD 65. (A) No evidence for AMH expression was evident in either the cortical (Cx) or the medullary (Med) regions of the fetal ovary. (B) Clusters of cells within the medulla were strongly positive for $3 \beta \mathrm{HSD}$. The connective tissue boundary separating cortex from medulla is indicated by arrows. (C) Clusters of medullary cells and a few cells scattered through the cortex stained intensely for 3BHSD. (D) P450c17 expression was intense in cells within the ovarian medulla and among cells in the outer cortex. (E) Medullary cells expressing P450c17 were apparently lipid-laden and arranged in clusters. (F) Cytochrome b5 expression, like 3ßHSD and P450c17, was evident in medullary cell clusters. Though present, cytochrome b5 expression was much less intense among scattered cortical cells.

was localized clearly in the syncytiotrophoblast and to a lesser degree in the cytotrophoblast of hyena placental sections (data not shown).

To the extent that was possible, the potential for androgen synthesis in male and female tissues was supported by measurements of steroids in fetal blood (Table 2). In sampled female fetuses, plasma androstenedione levels were 100-fold higher at GD 65 than at GD 45, and remained so in the female fetus collected at
GD 95. Testosterone (and DHT) concentrations were $<0.5 \mathrm{ng} / \mathrm{ml}$ at all ages and estradiol was below the limits of assay detection (data not shown). In both mixed twins examined, androstenedione and testosterone concentrations were numerically higher in the males than in the sibling females. Androstenedione was numerically higher than testosterone in males (Table 2), DHT concentrations averaged $<1 \mathrm{ng} / \mathrm{ml}$ and estradiol was again undetectable.
Ovary and testis GD 95

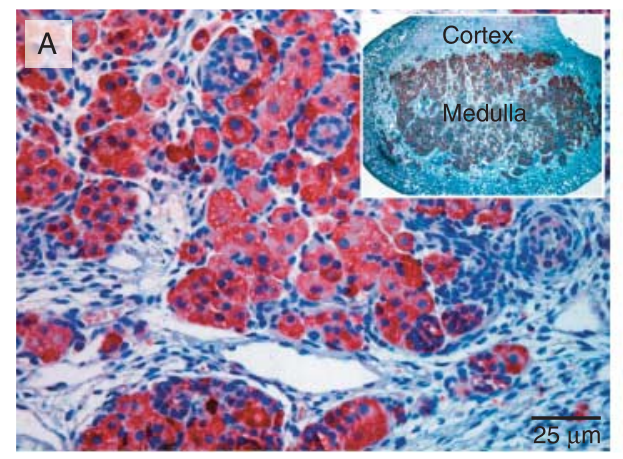

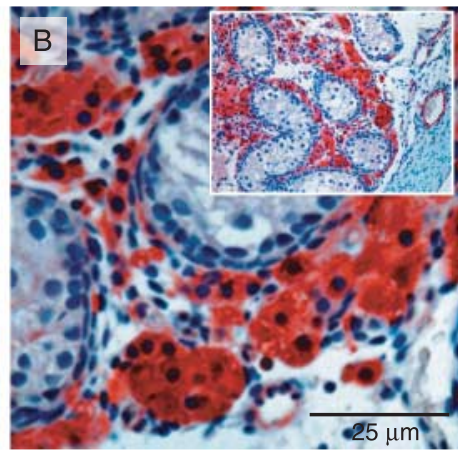

Figure 6 Immunohistochemistry for expression (in red) of $3 \beta$-hydroxysteroid dehydrogenase (3BHSD) in fetal gonads from GD 95. (A) Fetal ovary showing cytoplasmic expression of $3 \beta \mathrm{HSD}$ throughout the extensive medulla (insert). (B) Fetal testis showing $3 \beta \mathrm{HSD}$ expression in the cytoplasm of Leydig cells throughout the interstitium. 


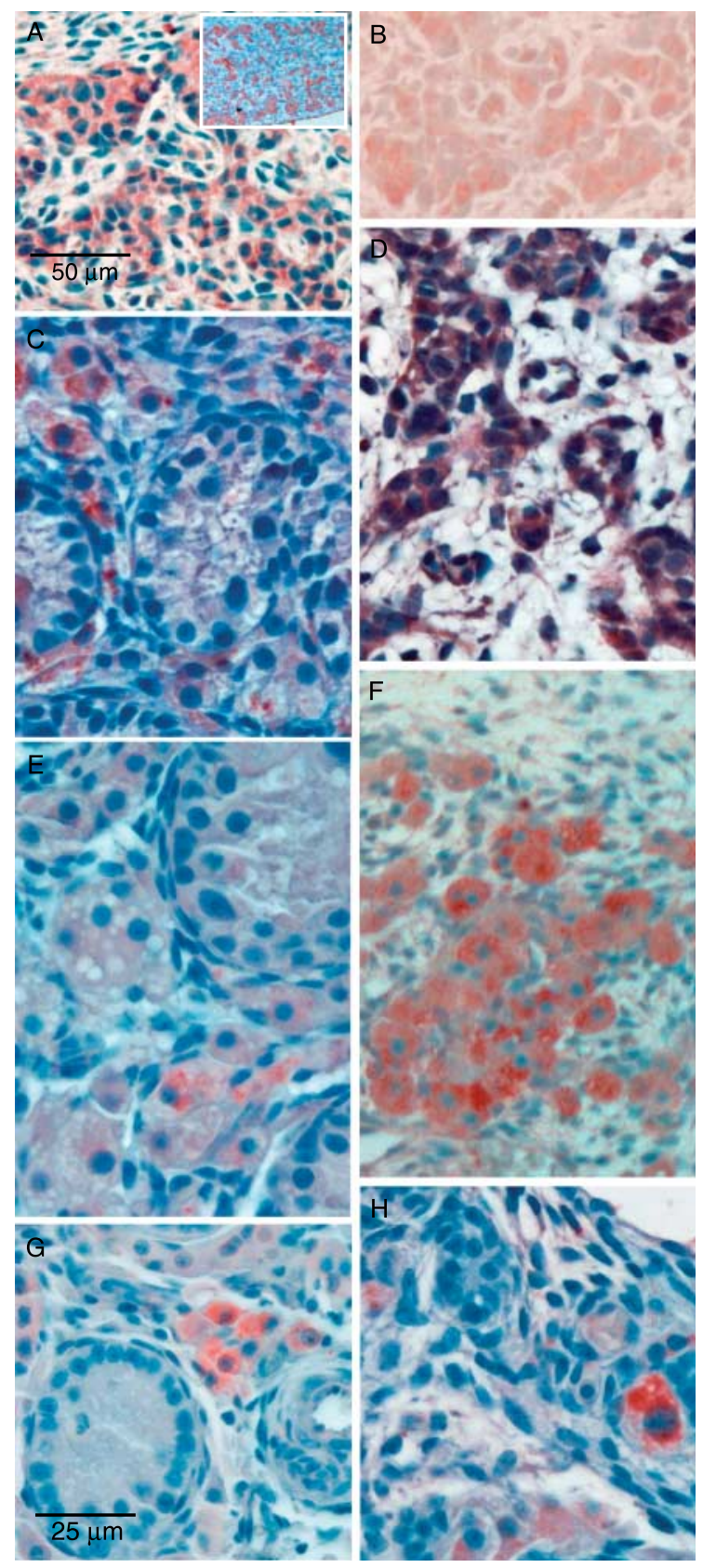

Figure 7 Immunohistochemistry for expression (in red) of side-chain cleavage cytochrome P450 (P450scc) in male (left panels) and female (right panels) fetal spotted hyena gonads from early (upper) to late (lower) gestation. (A) Fetal testis at GD 30. Note that expression is localized in developing Sertoli cells, especially those around the periphery of the testis, as seen for AMH (Fig. 2A). (B) Fetal ovary at GD 30 lacked detectable P450scc expression. (C) Fetal testis at GD 45 showing expression in Leydig cells and much lower levels in Sertoli cells inside tubules. (D) Fetal ovary at GD 45. P450scc expression is evident in cells of the developing cortical cords. (E) Fetal testis at GD 65 exhibiting a similar pattern of expression as that seen at GD 45. (F) Fetal ovary at GD 65 showing expression prominently in large cells within nests in the ovarian medulla. Note that the little expression was detected in cells of the cortex at this stage. (G) Fetal testis at GD 95 showing expression almost exclusively in Leydig cells and much less in Sertoli cells. (H) Fetal ovary at GD 95 exhibiting a similar pattern of medullary staining to that seen at GD 65.
Table 2 Fetal plasma androgen concentrations $(\mathrm{ng} / \mathrm{ml})$ at different gestational days $(\mathrm{GD})$.

\begin{tabular}{cccccc}
\hline & \multicolumn{2}{c}{ Female } & & \multicolumn{2}{c}{ Male } \\
\cline { 2 - 3 } \cline { 5 - 6 } \cline { 5 - 6 } & Androstenedione & Testosterone & & Androstenedione & Testosterone \\
\hline GD 45 & $<0.5$ & 0.37 & & NA & NA \\
GD 65 & 5.88 & 0.40 & & 7.57 & 3.69 \\
GD 95 & 3.63 & 0.33 & & 6.89 & 4.35 \\
\hline
\end{tabular}

NA, not available.

\section{Discussion}

The present data support the hypothesis that masculinization of the external genitalia in the female spotted hyena occurs well before the capacity for androgen synthesis can be detected in fetal ovaries. The reported gonadal morphology of male and female spotted hyena fetuses is consistent with that described by Lindeque \& Skinner (1982) and Licht et al. (1998). Genital tubercle morphogenesis was well advanced in the earliest male and female specimens examined here (GD 30) as reported previously (Cunha et al. 2005). Based on $\mathrm{AMH}, \mathrm{P} 450 \mathrm{c} 17,3 \beta \mathrm{HSD}$, and P450scc expression, testicular but not the ovarian differentiation, was observed at GD 30. The first signs of ovarian androgensynthesizing capacity appeared in our GD 45 specimen. Despite ovarian interstitial expression of P450c17, cytochrome b5, 3ßHSD and P450scc on GD 45, plasma androstenedione concentration was undetectable in the female at GD 45. By GD 65 however, when all enzymes were expressed in a well-organized ovarian medulla, androstenedione concentration was comparable with that of the male twin, and similar to previously reported concentrations in male and female fetal plasma (Lindeque \& Skinner 1982, Licht et al. 1992). The expression of P450scc, 33HSD, P450c17, and cytochrome b5 suggests that fetal gonads express all enzymes necessary for efficient androgen synthesis. However, Licht et al. also reported fetal progesterone concentrations exceeding $1000 \mathrm{ng} / \mathrm{ml}$ (Licht et al. 1992), suggesting that substrate for androgen synthesis may be just as readily available from the fetal circulation. When taken together with androstenedione concentrations in fetal plasma, these data suggest that ovarian androgen synthesis though initiated in spotted hyena fetuses as early as GD 45, increased to levels measurable in plasma by GD 65. Enzyme expression in late gestation fetal ovaries was consistent with high androgen levels reported previously for umbilical and fetal jugular blood (Licht et al. 1992). The delay in fetal ovarian steroidogenic differentiation until GD 45, or later, provides further support for the hypothesis that formation of the peniform clitoris of female spotted hyenas by GD 30 occurs without appreciable influence of androgens from the fetal gonad.

The results presented here suggest that androgens are likely to influence critical aspects of sexual development 
in male and female spotted hyenas but within different developmental windows. Recent studies have shown that male genital differentiation is androgen-dependent, even if androgens do not initiate the growth of the genital tubercle. Treatment of pregnant females with the androgen receptor blocker flutamide, and the $5 \alpha$ reductase enzyme inhibitor finasteride (anti-androgen treatment), increases the elasticity of the meatus of offspring that developed under anti-androgen therapy (Drea et al. 1998). Males from anti-androgen-treated pregnancies also exhibited more female typical penile development, including a shorter and thicker shaft, with retractor penis muscle insertion dorsal rather than ventral to the urethra, all of which are established between GD 30 and 45 (Cunha et al. 2005). Coincident with this early virilization in males, the GD 30 fetal testis exhibited clear evidence of endocrinological differentiation including expression of key enzymes necessary for androgen synthesis, as well as AMH. In contrast, fetal ovaries appear to be fully capable of androgen synthesis only after GD 45, leaving at least a 15-day window during which genital morphology develops without the androgen stimulation experienced by males (Cunha et al. 2005). Androgen receptor expression was evident in the retractor muscles of females, as well as males, and therefore the genital tubercle has equal potential for masculinization in both the sexes (Cunha et al. 2005). Thus, the initial delay in differentiation of fetal ovaries may be as crucial for normal female development in spotted hyenas as the relative lack of ovarian differentiation in other female mammals. In contrast, differentiation and androgen synthesis by the fetal ovarian medulla during the second half of gestation may drive development of aggression observed among female neonates. Twins in a typical hyena litter fight within minutes of birth, and levels of aggression are higher in female-female litters than in litters containing at least one male (Drea et al. 1996). In addition, female dominance over males appears during the first year of life in mixed-sex litters (Smale 1995). The present data support the hypothesis that, the fetal ovary is not a passive structure in spotted hyenas, but actively secretes androgens during the latter stages of gestation. This may be very important in establishing behaviors, especially in the neonatal period, when for example, rough and tumble play is organized in the brain of the rhesus monkey (Goy et al. 1988).

Endocrine function of the fetal testis does not have as immediate or as profound an influence on even the internal genitalia as might be expected. The gonadal specimens used for the present study were dissected to facilitate other work reported recently (Cunha et al. 2005), and definitive information on the presence and/or absence of the Wolffian and Müllerian ducts was not obtained for all fetuses. However, limited observations on genital duct regression from this study coupled with those reported previously may have important implications. Licht et al. (1998) noted that both Wolffian and Müllerian ducts were still obvious at day 48 of gestation in female fetuses, but male and female duct development is complete by GD 60-70 (Lindeque \& Skinner 1982), if recalculated from the reported fetal weights. Thus, Müllerian duct regression in male fetuses apparently takes weeks to complete after Sertoli cells are capable of AMH secretion (GD 30). Pigs experience a comparable delay between $\mathrm{AMH}$ expression and Müllerian duct regression (Inomata et al. 1993), although these events are more synchronous and rapid in dogs (Meyers-Wallen et al. 1991). Wolffian ducts persist in both females and males, during an interval when only the fetal testis expresses the enzymes necessary for androgen synthesis. Other sites of potential androgen synthesis were unexpectedly identified in males, as evidenced by strong P450c17 expression in the male Müllerian duct. The marked reduction in staining after pre-adsorption of the primary antisera, together with the cell-specific expression in gonads, and the specificity of the antisera when used in immunoblot analysis (unpublished observations) support the finding. Ovine mesonephros secretes steroids in culture, and the male organ secretes more testosterone than the female (Lun et al. 1998). Though the exact cellular site of steroid synthesis within the mesonephros was not determined, Müllerian duct was undoubtedly still attached, and P450c17 is expressed in non-gonadal tissues, including liver (Vianello et al. 1997), stomach (Dalla et al. 1995), kidney (Dalla et al. 2002), and brain (Compagnone et al. 1995). Clearly, additional confirmation is required, but if true, the male Müllerian duct may provide a significant, additional source of androgen in males, one that begins before testes differentiate, terminating when the ducts regress. Wolffian ducts also persist for a considerable period in female fetuses despite an apparent lack of androgen stimulation (Inomata et al. 1993) suggested both by the delay of ovarian differentiation noted here and by the feminine positioning of the retractor penis muscles. It is also well known that androgen production by differentiating male fetuses can affect female siblings in utero, at least in some litter-bearing species(vom Saal 1981). Placental aromatase activity likely modulates the effects of androgens on female differentiation, given that female babies with congenital P450arom deficiency are severely virilized (Grumbach \& Auchus 1999). In utero positional effects of male siblings on female piglets is much more subtle than in rodents (Rohde Parfet et al. 1990, Drickamer et al. 1997, 1999), probably because of the protective effect of P450arom expressed in the porcine placenta (Corbin et al. 1995) and the lack of P450arom in the rodent placenta (Mendelson et al. 2005). The higher concentrations of estradiol in male than female pig placentas (Choong \& Raeside 1974) likely reflect aromatization of male testosterone. Aromatase activity in the spotted hyena placenta is more than twice that of pig placenta (Conley et al. unpublished observations) and so is 
probably also protective of female fetuses. The failure to detect P450arom expression in hyena fetal ovaries or testes suggests that levels in these tissues are much lower than placenta and unlikely to influence androgen output from gonads of either sex. Even in neonatal boars, where testicular aromatase activity is quite high, estrogen production represents a fraction of the capacity for gonadal androgen synthesis (Moran et al. 2002).

In conclusion, the data presented here are consistent with the hypothesis that initial phallic development in the spotted hyena is largely androgen independent, but that differentiation of the fetal gonads, and their ability to synthesize androgens, is still important in sexual differentiation. In male hyenas, androgen synthesis by the fetal testes probably directs genital virilization. However, it is equally important that the female fetus experiences a window of development without androgen exposure to ensure placement of the retractor muscles dorsal to the urethra in the peniform clitoris, and maximize pleating and elasticity of the future birth canal. Since the hyena fetal ovary develops a medulla that is very active in androgen synthesis, the delay in its differentiation may be crucial for normal fertility. The peniform clitoris and complete lack of a vulva make the female spotted hyena unique among mammals, but the synthesis and local exposure of genital tissues to androgens from the fetal gonads, and possibly other extra-gonadal sources, must still be carefully regulated in both the sexes for proper reproductive development. Finally, androgen synthesis by the fetal ovaries and placenta, during the later stages of fetal life, may provide crucial endocrine support for organization of the neural substrates underlying neonatal aggression in spotted hyenas. Late-gestation androgenization of females could also play an essential role in neural organization that will be activated during adult life.

\section{Acknowledgements}

The authors thank Mary Weldele and staff at the University of California Berkeley Field Station for assistance with animals, Samantha Mapes, Jo Corbin, and Ann Nguyen for their expert technical assistance, and Dianne Anderson for the genetic sexing of early hyena fetuses. This work was supported by National Institutes of Health grant $\mathrm{MH}-39917$. The authors declare that there is no conflict of interest that would prejudice the impartiality of this scientific work.

\section{References}

Choong CH \& Raeside JI 1974 Chemical determination of oestrogen distribution in the foetus and placenta of the domestic pig. Acta Endocrinologica 77 171-185.

Compagnone NA, Bulfone A, Rubenstein JL \& Mellon SH 1995 Steroidogenic enzyme P450c17 is expressed in the embryonic central nervous system. Endocrinology 136 5212-5223.

Conley AJ \& Bird IM 1997 The role of cytochrome P450 17 alphahydroxylase and 3 beta-hydroxysteroid dehydrogenase in the integration of gonadal and adrenal steroidogenesis via the delta 5 and delta 4 pathways of steroidogenesis in mammals. Biology of Reproduction $\mathbf{5 6}$ 789-799.

Corbin CJ, Khalil MW \& Conley AJ 1995 Functional ovarian and placental isoforms of porcine aromatase. Molecular and Cellular Endocrinology 113 29-37.

Cunha GR, Wang Y, Place NJ, Liu W, Baskin L \& Glickman SE 2003 Urogenital system of the spotted hyena (Crocuta crocuta Erxleben): a functional histological study. Journal of Morphology 256 205-218.

Cunha GR, Place NJ, Baskin L, Conley A, Weldele M, Cunha TJ, Wang YZ, Cao M \& Glickman SE 2005 The ontogeny of the urogenital system of the spotted hyena (Crocuta crocuta Erxleben). Biology of Reproduction 73 554-564.

Dalla VL, Couet J, Labrie Y, Simard J, Belvedere P, Simontacchi C, Labrie F \& Colombo L 1995 Occurrence of cytochrome P450c17 mRNA and dehydroepiandrosterone biosynthesis in the rat gastrointestinal tract. Molecular and Cellular Endocrinology 111 83-92.

Dalla VL, Vianello S, Belvedere P \& Colombo L 2002 Rat cytochrome P450c17 gene transcription is initiated at different start sites in extraglandular and glandular tissues. Journal of Steroid Biochemistry and Molecular Biology 82 377-384.

Drea CM, Hawk JE \& Glickman SE 1996 Aggression decreases as play emerges in infant spotted hyaenas: preparation for joining the clan. Animal Behaviour 51 1323-1336.

Drea CM, Weldele ML, Forger NG, Coscia EM, Frank LG, Licht P \& Glickman SE 1998 Androgens and masculinization of genitalia in the spotted hyaena (Crocuta crocuta). 2. Effects of prenatal antiandrogens. Journal of Reproduction and Fertility 113 117-127.

Drea CM, Coscia EM \& Glickman SE 1999 Hyenas. In Encyclopedia of Reproduction, pp 718-725. Eds E Knobil, J Neill \& P Licht. San Diego: Academic Press.

Drickamer LC, Arthur RD \& Rosenthal TL 1997 Conception failure in swine: importance of the sex ratio of a female's birth litter and tests of other factors. Journal of Animal Science 75 2192-2196.

Drickamer LC, Rosenthal TL \& Arthur RD 1999 Factors affecting the number of teats in pigs. Journal of Reproduction and Fertility 115 97-100.

Forger NG, Frank LG, Breedlove SM \& Glickman SE 1996 Sexual dimorphism of perineal muscles and motoneurons in spotted hyenas. Journal of Comparative Neurology 375 333-343.

Frank LG, Glickman SE \& Powch I 1990 Sexual dimorphism in the spotted hyena (Crocuta crocuta). Journal of Zoology 221 308-313.

Glickman SE 1995 The spotted hyena from Aristotle to the Lion King: reputation is everything. Social Research 62 501-537.

Goy RW, Bercovitch FB \& McBrair MC 1988 Behavioral masculinization is independent of genital masculinization in prenatally androgenized female rhesus macaques. Hormones and Behavior 22 552-571.

Grumbach MM \& Auchus RJ 1999 Estrogen: consequences and implications of human mutations in synthesis and action. Journal of Clinical Endocrinology and Metabolism 84 4677-4694.

Inomata $T$, Inoue S, Sugawara $H$, Kajihara $H$, Shinomiya T, Wagai I, Ninomiya H, Oshida T, Shirai M \& Hashimoto Y 1993 Developmental changes in paramesonephric and mesonephric ducts and the external genitalia in swine fetuses during sexual differentiation. Journal of Veterinary Medical Science 55 371-378.

Licht P, Frank LG, Pavgi S, Yalcinkaya TM, Siiteri PK \& Glickman SE 1992 Hormonal correlates of 'masculinization' in female spotted hyaenas (Crocuta crocuta). 2. Maternal and fetal steroids. Journal of Reproduction \& Fertility 95 463-474.

Licht P, Hayes T, Tsai P, Cunha G, Kim H, Golbus M, Hayward S, Martin MC, Jaffe RB \& Glickman SE 1998 Androgens and masculinization of genitalia in the spotted hyaena (Crocuta crocuta). 1. Urogenital morphology and placental androgen production during fetal life. Journal of Reproduction \& Fertility 113 105-116.

Lindeque M \& Skinner JD 1982 Fetal androgens and sexual mimicry in spotted hyaenas (Crocuta crocuta). Journal of Reproduction \& Fertility 65 405-410. 
Lun S, Smith P, Lundy T, O'Connell A, Hudson N \& McNatty KP 1998 Steroid contents of and steroidogenesis in vitro by the developing gonad and mesonephros around sexual differentiation in fetal sheep. Journal of Reproduction \& Fertility 114 131-139.

Mapes S, Corbin CJ, Tarantal A \& Conley A 1999 The primate adrenal zona reticularis is defined by expression of cytochrome b5, 17alphahydroxylase/17,20-lyase cytochrome P450 (P450c17) and NADPHcytochrome P450 reductase (reductase) but not 3beta-hydroxysteroid dehydrogenase/delta5-4 isomerase (3beta-HSD). Journal of Clinical Endocrinology and Metabolism 84 3382-3385.

Mapes S, Tarantal AF, Parker CR, Moran FM, Bahr JM, Pyter L \& Conley AJ 2002 Adrenocortical cytochrome b5 expression during fetal development of the rhesus macaque. Endocrinology 143 1451-1458.

Matthews LH 1939 Reproduction in the spotted hyaena, Crocuta crocuta (erxleben). Proceedings of the Royal Society of London. Series B. Biological Sciences 230 1-78.

Mendelson CR, Jiang B, Shelton JM, Richardson JA \& Hinshelwood MM 2005 Transcriptional regulation of aromatase in placenta and ovary. Journal of Steroid Biochemistry and Molecular Biology 95 25-33.

Meyers-Wallen VN, Manganaro TF, Kuroda T, Concannon PW, MacLaughlin DT \& Donahoe PK 1991 The critical period for mullerian duct regression in the dog embryo. Biology of Reproduction 45 626-633.

Miller WL 2005 Minireview: regulation of steroidogenesis by electron transfer. Endocrinology 146 2544-2550.

Moran FM, Ford JJ, Corbin CJ, Mapes S, Njar VC, Brodie AM \& Conley AJ 2002 Regulation of microsomal P450, redox partner proteins and steroidogenesis in the developing testes of the neonatal pig. Endocrinology 143 3361-3369.

Neaves WB, Griffin JE \& Wilson JD 1980 Sexual dimorphism of the phallus in spotted hyaena (Crocuta crocuta). Journal of Reproduction and Fertility 59 509-513.

Place NJ \& Glickman SE 2004 Masculinization of female mammals: lessons from nature. Advances in Experimental Medicine and Biology 545 243-253.

Place NJ, Weldele ML \& Wahaj SA 2002 Ultrasonic measurements of second and third trimester fetuses to predict gestational age and date of parturition in captive and wild spotted hyenas Crocuta crocuta. Theriogenology 58 1047-1055.
Pomp D, Good BA, Geisert RD, Corbin CJ \& Conley AJ 1995 Sex identification in mammals with polymerase chain reaction and its use to examine sex effects on diameter of day-10 or -11 pig embryos. Journal of Animal Science 73 1408-1415.

Rohde Parfet KA, Lamberson WR, Rieke AR, Cantley TC, Ganjam VK, vom Saal FS \& Day BN 1990 Intrauterine position effects in male and female swine: subsequent survivability, growth rate, morphology and semen characteristics. Journal of Animal Science 68 179-185.

Sinclair AH, Berta P, Palmer MS, Hawkins JR, Griffiths BL, Smith MJ, Foster JW, Frischauf AM, Lovell-Badge $R$ \& Goodfellow PN 1990 A gene from the human sex-determining region encodes a protein with homology to a conserved DNAbinding motif. Nature 346 240-244.

Smale L 1995 Frank A. Beach Award. Male-female dominance relations at three ontogenetic stages in the spotted hyena (Crocuta crocuta). Hormones and Behavior 29 127-130.

Vianello S, Waterman MR, Dalla VL \& Colombo L 1997 Developmentally regulated expression and activity of 17 alpha-hydroxylase/C-17,20-lyase cytochrome P450 in rat liver. Endocrinology 138 3166-3174.

vom Saal FS 1981 Variation in phenotype due to random intrauterine positioning of male and female fetuses in rodents. Journal of Reproduction and Fertility 62 633-650.

Wilson JD, George FW \& Renfree MB 1995 The endocrine role in mammalian sexual differentiation. Recent Progress in Hormone Research 50 349-364.

Wingfield JC, Hegner RE \& Lewis DM 1991 Circulating levels of luteinizing-hormone and steroid-hormones in relation to socialstatus in the cooperatively breeding white-browed sparrow weaver, Plocepasser-Mahali. Journal of Zoology 225 43-58.

Yalcinkaya TM, Siiteri PK, Vigne JL, Licht P, Pavgi S, Frank LG \& Glickman SE 1993 A mechanism for virilization of female spotted hyenas in utero. Science 260 1929-1931.

Received 27 January 2006

First decision 7 April 2006

Revised manuscript received 31 May 2006

Accepted 20 June 2006 